\title{
Cost and determinants of morbidity from work related disabling injuries in Taiwan
}

\author{
Yi-Hung Liu, Mau-Roung Lin, Jung-Der Wang
}

\begin{abstract}
Objectives-To estimate the cost and determinants of morbidity from work related disabilities.

Methods-114 people who lived in metropolitan Taipei and who had received disability compensation from the Labor Insurance Bureau from March to June, 1991 were randomly selected. There were 77 workers interviewed through a questionnaire that inquired about possible loss of productivity including the duration of morbidity, the ability to return to work, and any change in monthly income upon returning to work.
\end{abstract}

Results-The mean (SD) duration of a stay in hospital was 29 (39) days, median: 15 days. The average duration between discharge from the hospital and returning to work was 111 (146) days, median: 45 days. The main determinants of the duration of the stay in hospital were the number of stays in hospital and the severity of the injury. A multivariate linear analysis showed that old age and the severity of injury determine the durations of morbidity. An ordinal logistic regression analysis showed that the severity of injury, size of the factory, and age determined the magnitude of future productivity loss. Based on these models, it was estimated that the total duration of morbidity (in hospital and at home) due to occupational disability was 660000 person-days each year. When the percentage of the decrease in income because of permanent disability was converted into a loss of work days, the annual morbidity costs were about 19000-26000 personyears between 1985-1990.

Conclusion-The morbidity cost was about five times as high as the lump sum payment that a worker usually received for disability compensation. We conclude that morbidity cost should be evaluated carefully in the future for the establishment of accurate and fair disability compensation payments.

(Occup Environ Med 1995;52:138-142)

Keywords: occupational disability; morbidity cost; compensation

An average of one to two/thousand male workers in Taiwan sustain work related disabling injuries annually ${ }^{1-3}$; also, the annual mortality rate of male workers due to occupational injuries is about $0.5 /$ thousand. ${ }^{23}$ The risk of major occupational injuries among female workers is about one sixth that of male workers and has not shown any tendency to decline in the past six years. ${ }^{1-3}$ The total mortality due to occupational injuries in Taiwan is five to 10 times higher than that of more industrialised countries such as Japan or the United States. ${ }^{2}$

Besides the above figures, there are other reasons to call for continuous efforts and more allocation of resources for research and the prevention of occupational injuries. Most occupational injuries can be avoided if safety mechanisms are clearly understood and proper precautions followed. ${ }^{4-7}$ Furthermore, the social costs of occupational injuries are much greater than those of other health problems because the age group of injured workers is relatively young and they are economically productive. ${ }^{3}$

There are two key elements of social cost. One is the direct cost such as expenditures for goods and services. The other is the indirect cost that includes the loss of potential earning or loss of productivity. ${ }^{9}$ The indirect cost is usually several times higher than the direct cost. ${ }^{10}$ In occupational accidents, the indirect cost can be further divided into the mortality cost of occupational fatalities and the morbidity cost of occupational injuries. ${ }^{9}$

In this paper we try to estimate the cost and determinants of morbidity due to work related permanent physical impairment-that is, occupational disabilities, in Taiwan.

\section{Subjects and methods}

To draw a representative sample of workers with work related disabling injuries, we visited the Labor Insurance Bureau weekly during the months of March to June, 1991. Every worker who lived in the metropolitan Taipei area and had received his or her compensation in the previous week was registered and given a number. Through the procedure of random sampling, 114 people were selected. Additional information such as their address, the telephone numbers of their home and workplace, and the details of their injuries, etc were obtained from the Labor Insurance Bureau. To receive disability compensation resulting from occupational injuries, these workers had to have finished their initial medical treatment, and the disability should be relatively stable. All workers with an occupationally-related permanent disability will cer- 
Table 1 Comparison of the pattern of injuries and the degree of disabilities

\begin{tabular}{|c|c|c|c|}
\hline & $\begin{array}{l}\text { Interviewed } \\
n=77\end{array}$ & $\begin{array}{l}\text { Not interviewed } \\
n=37\end{array}$ & Pvalue \\
\hline \multicolumn{4}{|l|}{ Age (y): } \\
\hline Mean (SD) & $37 \cdot 3(11 \cdot 1)$ & $33 \cdot 6(11 \cdot 3)$ & 0.096 \\
\hline Range & $8-62$ & $16-57$ & \\
\hline Sex $M: F$ & $58: 19$ & $34: 3$ & $0.036 \dagger$ \\
\hline \multicolumn{4}{|l|}{ Injury: } \\
\hline Blindness due to eyeball injury & 1 & 0 & $0.39 \dagger$ \\
\hline Cervical and thoracic trauma & 2 & 2 & \\
\hline Lumbosacral trauma & 4 & 0 & \\
\hline Lower extremity & 3 & 1 & \\
\hline Bilateral upper extremities & 5 & 0 & \\
\hline Unilateral upper extremities & 60 & 34 & \\
\hline Finger(s) & 2 & 0 & \\
\hline \multicolumn{4}{|l|}{ Degree of disability: } \\
\hline $1-3 \ddagger$ & $3(2)$ & 1 & $0.68 \dagger$ \\
\hline $4-6 \ddagger$ & $2(1)$ & 1 & \\
\hline $7-9 \ddagger$ & $16(3)$ & 4 & \\
\hline $10-12 \ddagger$ & $27(1)$ & 21 & \\
\hline $13-15 \ddagger$ & $29(5)$ & 10 & \\
\hline \multicolumn{4}{|l|}{ Disability compensation (NT\$): } \\
\hline $\begin{array}{l}\text { Mean (SD) } \\
\text { Range } \\
\text { Median }\end{array}$ & $\begin{array}{l}113725\left(\begin{array}{lll}114 & 950) \\
15300-470 & 000 \\
71400\end{array}\right.\end{array}$ & $\begin{array}{rl}117938(155 & 851) \\
19 & 200-915000 \\
81 & 600\end{array}$ & $0 \cdot 82^{\star}$ \\
\hline \multirow{4}{*}{$\begin{array}{l}\text { Duration of stay in hospital: } \\
\text { Mean (SD) } \\
\text { Range } \\
\text { Median }\end{array}$} & & & \\
\hline & $23(36)$ & $46(129)$ & $0 \cdot 69^{\star}$ \\
\hline & $0-252$ & $0-738$ & \\
\hline & 13 & 11 & \\
\hline
\end{tabular}

$\star$ Wilcoxon rank-sum test. $\nmid \chi^{2}$ test. $\ddagger($ ) No of workers not returned to work.

tainly obtain their compensation payment because of workmen's compensation legislation in Taiwan. In the years 1985 to 1990 , there were 34416 workers who obtained compensation. ${ }^{3}$

After performing a pilot test, we designed a questionnaire $^{11-13}$ that inquired about possible loss of productivity including the duration of morbidity (in hospital and at home), any compensation payments or reimbursements received, whether the subjects could return to work, and if there were any changes in their incomes. We employed two groups of interviewers with three members in each group: one medical professional (a medical doctor or physical therapist) and two social workers. Each interviewer received a six hour interview training course and every item of inquiry was standardised. From July to November 1991, interviewers visited the selected workers.

Data were then coded into a computer and analysed by a statistical package SAS/STAT PC $6 \cdot 04 .{ }^{14} \mathrm{We}$ applied multiple linear regression analysis for the estimation of the duration of total morbidity including the duration of a stay in hospital and rest at home after acute injuries. Then, an ordinal logistic regression analysis $^{15}$ was also performed to obtain the adjusted odds ratio (OR) of all the determinants of future loss of productivity. We have classified the decrease in monthly income (in NT\$) into four ordinal categories: <5000, 5000-9999, 10 000-24 999, and $>25000$. The independent variables we put in to fit the model included age, sex, severity of injury, educational level, size of the factory, relationship to the employer, etc.

To estimate the total morbidity cost of work related disability in Taiwan, we can only use the severity of injury and age as the independent variables because no information on the other determinants is available at the national registration data. We have constructed a model to predict the magnitude of the person's future decrease in working capability. In this model, the proportion of change in monthly income was assumed to be a percentage of loss of working capability. The resulting models from the multiple regression were used to estimate the productivity lost due to morbidity for the years 1985 to 1990 . Each worker's future loss of productivity was calculated as the percentage of loss multiplied by his or her potential working years. To estimate the potential working years, we assumed that each worker would have worked until 65 years of age had he or she not been injured. Thus, we obtained the person's potential working years by subtracting the person's age from 65 . Both parts of the morbidity costthat is, the duration of the stay in hospital plus convalescence at home and the future loss of productivity—shared the same time unit: person-days or person-years.

\section{Results}

Among the 114 workers randomly selected, there were 92 men and 22 women. Their mean (SD) age was $36 \cdot 1(11 \cdot 3)$ with a range from 16-62. According to the regulations of the Labor Insurance Bureau, the degree of disability was classified, from severe to mild, on a scale of 1-15 ( 1 being the most severe)..$^{16}$ Most of the disabilities were mild-that is, $76.3 \%$ of the workers fell between $10-15$ on the severity scale. The age and sex distribution of these 114 workers, as well as the cause, agent, and severity of the injury, were similar to those of all disabled workers in Taiwan in $1990 .^{3}$

We successfully interviewed 77 workers; the interview rate was $67 \cdot 5 \%$. The mean (SD) duration from the onset of injury to the date of the interview was $10 \cdot 1(6 \cdot 7)$ months. Sixty five of them $(84 \%)$ had returned to work by the time of our study. There were 12 workers who could not be interviewed because of difficulties in making an appointment. Other common reasons for a lack of an interview were either a change in place of employment and moving out of metropolitan Taipei, or a loss of contact with their families (21/37). Three people refused to be interviewed and one person died. Other than the distribution of sex, there was no significant difference in the characteristics of those interviewed and those who were not (table 1).

The mean (SD) duration of a stay in hospital for the 77 people interviewed was 29 (39) days, median: 15 days. The number of stays in hospital ranged from 0 to 6 . The degree of disability was further categorised into severe (degree 1-3), moderate (degree 4-9), and mild (degree 10-15). The duration of convalescence at home (after discharge from the hospital and before returning to work) was about five times longer than that of the stay in hospital, and the variability of the convalescence was also greater (table 2). The total duration of morbidity was the sum of the stays in hospital and at home.

Both the number of times a patient was admitted to hospital and the severity of the disability (but not age) were important determinants in the multiple linear regression 
Table 2 Duration of morbidity (in hospital or at home) among disabled workers (stratified by the severity of the disability)

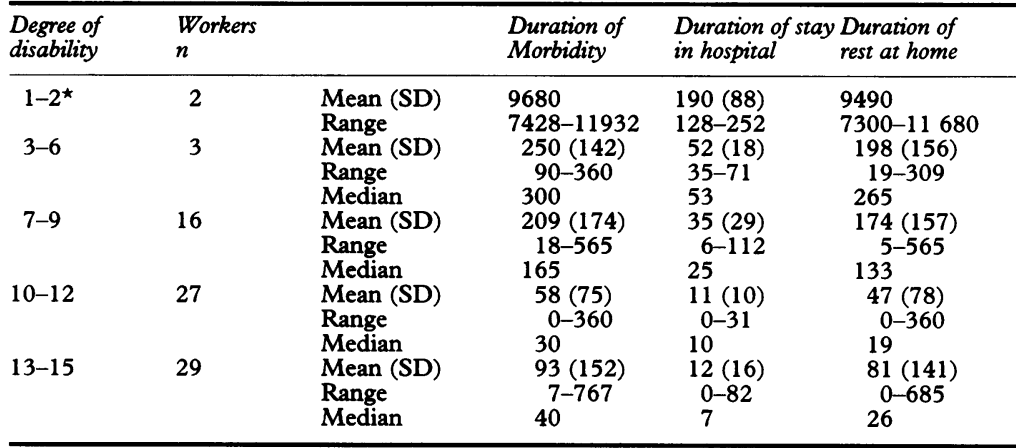

*Two workers who had been bedridden for two years after their injury were assumed to be unable to work until the retirement age of 65 .

analysis of the duration of the stay in hospital. Except for the two most severely injured workers (degree of disability 1-2 on table 2, namely, confined to bed) the 75 workers we visited had an average duration of convalescence at home of 111 (146) days, median: 45 days. Results of the multiple regression analysis of convalescence at home and durations of morbidity of these 75 workers showed that

Table 3 Models constructed from multiple linear regression to predict the duration of stay in hospital, rest at home, and total morbidity *

\begin{tabular}{|c|c|c|c|c|}
\hline $\begin{array}{l}\text { Dependent } \\
\text { variable }\end{array}$ & $\begin{array}{l}\text { Independent } \\
\text { variables }\end{array}$ & $\begin{array}{l}\text { Parameter } \\
\text { estimate }\end{array}$ & Pvalue & $R^{2}$ \\
\hline \multirow{3}{*}{$\begin{array}{l}\text { Duration of stay } \\
\text { in hospital }\end{array}$} & Intercept & $66 \cdot 7$ & 0.0001 & \multirow[t]{3}{*}{0.66} \\
\hline & $\begin{array}{l}\text { Degree of } \\
\text { severity }(1-15)\end{array}$ & $-5 \cdot 8$ & 0.0001 & \\
\hline & $\begin{array}{l}\text { Number of stays } \\
\text { in hospital }\end{array}$ & $19 \cdot 0$ & $0 \cdot 0001$ & \\
\hline \multirow{3}{*}{$\begin{array}{l}\text { Duration of } \\
\text { rest at home }\end{array}$} & Intercept & $272 \cdot 5$ & $0 \cdot 0050$ & \multirow[t]{3}{*}{0.35} \\
\hline & $\begin{array}{l}\text { Degree of } \\
\text { severity }(1-15)\end{array}$ & $-28 \cdot 6$ & 0.0001 & \\
\hline & Age & $4 \cdot 4$ & 0.0085 & \\
\hline \multirow{3}{*}{$\begin{array}{l}\text { Duration of } \\
\text { morbidity }\end{array}$} & Intercept & 392.6 & 0.0002 & \multirow[t]{3}{*}{$0 \cdot 38$} \\
\hline & $\begin{array}{l}\text { Degree of } \\
\text { severity }(1-15)\end{array}$ & $-37 \cdot 3$ & 0.0001 & \\
\hline & Age & $4 \cdot 1$ & 0.0160 & \\
\hline
\end{tabular}

*Other independent variables, such as educational level $(P=0.63)$, the size of the factory judged by number of workers $(P=0.92)$, relation with the employer $(P=0.67)$ were not included in the model because they were not significant. The two workers with permanent disability were excluded from the model of the duration of rest at home and morbidity to downgrade their influence on the models.

Table 4 Decrease in monthly income stratified by demographic and other characteristics of the disabled workers

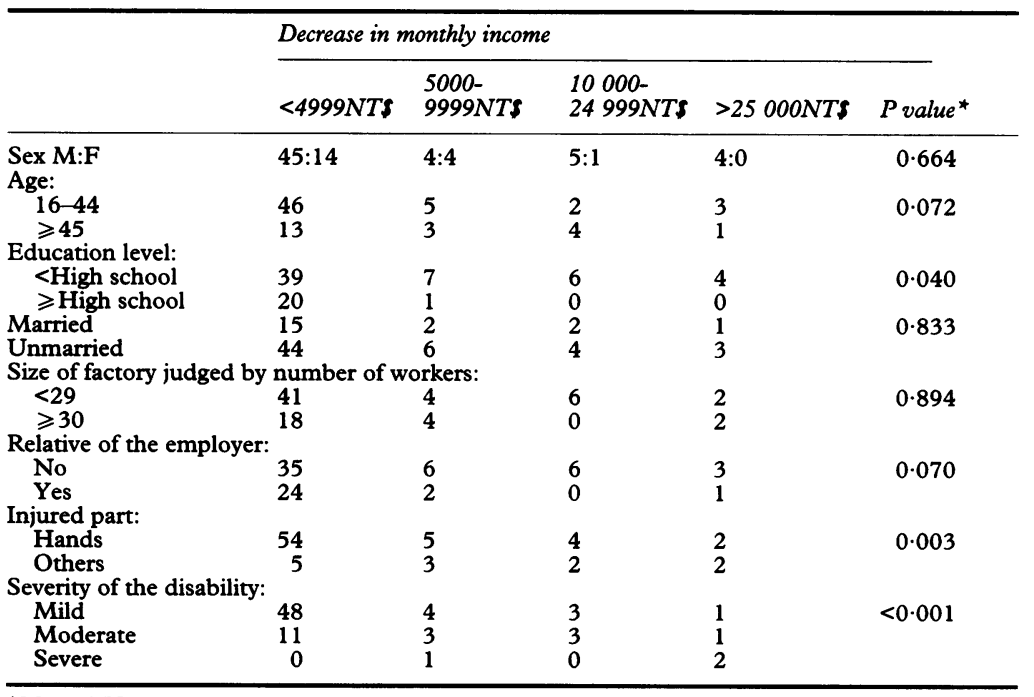

${ }^{\star}$ Mantel-Haenszel $\chi^{2}$ test for trends. these two dependent variables shared the same determinants - that is, the age of the worker and the severity of the injury (table 3).

In exploring each person's future loss of productivity, we calculated the decrease in income after the documentation of permanent disability. The decrease in monthly income was stratified and analysed by the MantelHaenszel $\chi^{2}$ test for trends. Table 4 shows that there is a trend in the decrease of monthly income associated with a more severe injury $(P<0.0001)$, an injury that involved parts other than the hands $(P=0.003)$, or a lower educational level $(P=0.04)$. Also, an ordinal logistic registic regression analysis was performed to explore the determinants of the decrease in monthly income. The result showed that after adjustment for various factors, an increase in the severity of injury, a decrease in size of the factory, or an older age are independently associated with an increased OR of greater loss in monthly income (table 5).

With the proportion of decrease in monthly income as the dependent variable, a multiple linear regression model was constructed to explore the importance of the age of the worker and the severity of the injury. The proportion of decrease in monthly income for those over 45 years of age showed a dramatic increase $(14.6 \%)$. Moreover, the severity of the injury sustained by the worker also significantly determined the magnitude of decrease in the person's monthly income (table 6). The total duration of morbidity due to occupational disability, inferred from the model, was about 660000 person-days, or 1808 personyears, annually for the past six years. The average morbidity cost for each disabled

Table 5 Adjusted ORs of different independent variables for loss of productivity calculated from an ordinal logistic regression analysis (the dependent variables are the four different levels of decrease in monthly income-1st row of table 4)

\begin{tabular}{|c|c|c|}
\hline Independent variables & Adjusted OR (95\% CI) & $P$ value \\
\hline \multicolumn{3}{|l|}{ Severity of injury: } \\
\hline $\begin{array}{l}\text { Mild } \\
\text { Moderate }\end{array}$ & $\begin{array}{l}1.0 \\
0.19(0.70 \text { to } 0.054)\end{array}$ & \\
\hline $\begin{array}{l}\text { Moderate } \\
\text { Severe }\end{array}$ & $0.004(0.10$ to 0.0002$)$ & $<0.001$ \\
\hline \multicolumn{3}{|c|}{ Size of factory (by number of workers): } \\
\hline $\begin{array}{l}<29 \\
\geqslant 30\end{array}$ & $\begin{array}{l}0.16(0.80 \text { to } 0.029) \\
1.0\end{array}$ & 0.03 \\
\hline \multicolumn{3}{|c|}{$1 \cdot 0$} \\
\hline $\begin{array}{l}16-44 \\
\geqslant 45\end{array}$ & $\begin{array}{l}1.0 \\
0.29(0.94 \text { to } 0.086)\end{array}$ & 0.05 \\
\hline \multicolumn{3}{|c|}{ Relatives of the employer: } \\
\hline $\begin{array}{l}\text { No } \\
\text { Yes }\end{array}$ & $\begin{array}{l}0.27(1.19 \text { to } 0.058) \\
1.0\end{array}$ & 0.08 \\
\hline \multicolumn{3}{|l|}{ Education level: } \\
\hline $\begin{array}{l}<\text { High school } \\
\geqslant \text { High school }\end{array}$ & $\begin{array}{l}0.26(2.38 \text { to } 0.028) \\
1.0\end{array}$ & $0 \cdot 23$ \\
\hline
\end{tabular}

Table 6 Proportion of decrease in monthly income predicted by the multiple regression model stratified by age and severity of the injury

\begin{tabular}{llc}
\hline Age (y) & Severity & $\begin{array}{l}\text { Decrease in monthly } \\
\text { income (\%) }\end{array}$ \\
\hline$<44$ & Mild (10-15) & $7 \cdot 34$ \\
& Moderate (4-9) & $24 \cdot 73$ \\
& Severe (1-3) & $87 \cdot 37$ \\
& Mild (10-15) & $21 \cdot 93$ \\
& Moderate (4-9) & $39 \cdot 32$ \\
& Severe (1-3) & $100 \cdot 0$ \\
\hline
\end{tabular}


Table 7 Morbidity costs (in person-years) of occupational disabilities in Taiwan 1985-90, estimated by our models from tables 3 and 6

\begin{tabular}{|c|c|c|c|c|c|c|}
\hline $\begin{array}{l}\text { Calendar } \\
\text { year }\end{array}$ & Severity of injury & Victims (n) & $\begin{array}{l}\text { Duration of } \\
\text { morbidity }(y)\end{array}$ & $\begin{array}{l}\text { Productivity } \\
\text { loss }(\times 100 y)\end{array}$ & $\begin{array}{l}\text { Total morbidity } \\
\text { cost }(\times 100 y)\end{array}$ & $\begin{array}{l}\text { Morbidity } \\
\text { costs/ } \\
\text { person (y) }\end{array}$ \\
\hline \multirow[t]{4}{*}{1985} & Total & 5358 & 186 & 206 & 224 & $4 \cdot 2$ \\
\hline & Severe (1-3) & 156 & 220 & 24 & 26 & $16 \cdot 5$ \\
\hline & Moderate (4-9) & 1042 & 790 & 70 & 78 & $7 \cdot 4$ \\
\hline & Mild (10-15) & 4160 & 840 & 112 & 121 & $2 \cdot 9$ \\
\hline \multirow[t]{4}{*}{1986} & Total & 6002 & 1870 & 223 & 242 & $4 \cdot 0$ \\
\hline & Severe $(1-3)$ & 114 & 160 & 18 & 20 & $17 \cdot 6$ \\
\hline & Moderate (4-9) & 955 & 670 & 70 & 77 & $8 \cdot 1$ \\
\hline & Mild (10-15) & 4932 & 1030 & 135 & 145 & $2 \cdot 9$ \\
\hline \multirow[t]{4}{*}{1987} & Total & 6496 & 2140 & 244 & 265 & $4 \cdot 1$ \\
\hline & Severe $(1-3)$ & 167 & 240 & 24 & 26 & $15 \cdot 7$ \\
\hline & Moderate (4-9) & 1078 & 770 & 77 & 85 & $7 \cdot 8$ \\
\hline & Mild $(10-15)$ & 5243 & 1120 & 143 & 154 & $2 \cdot 9$ \\
\hline \multirow[t]{4}{*}{1988} & Total & 6163 & 1980 & 227 & 247 & $4 \cdot 0$ \\
\hline & Severe $(1-3)$ & 123 & 180 & 20 & 21 & $17 \cdot 4$ \\
\hline & Moderate (4-9) & 1003 & 710 & 73 & 81 & $8 \cdot 0$ \\
\hline & Mild (10-15) & 5022 & 1100 & 134 & 145 & $2 \cdot 9$ \\
\hline \multirow[t]{4}{*}{1989} & Total & 5617 & 1760 & 206 & 223 & $4 \cdot 0$ \\
\hline & Severe $(1-3)$ & 118 & 170 & 19 & 21 & $17 \cdot 9$ \\
\hline & Moderate (4-9) & 853 & 600 & 63 & 69 & $8 \cdot 1$ \\
\hline & Mild $(10-15)$ & 4634 & 990 & 123 & 133 & $2 \cdot 9$ \\
\hline \multirow[t]{4}{*}{1990} & Total & 4780 & 1520 & 177 & 192 & $4 \cdot 0$ \\
\hline & Severe (1-3) & 101 & 140 & 19 & 20 & $20 \cdot 2$ \\
\hline & Moderate (4-9) & 757 & 530 & 55 & 61 & $8 \cdot 0$ \\
\hline & Mild (10-15) & 3910 & 850 & 102 & 110 & $2 \cdot 8$ \\
\hline
\end{tabular}

worker was equal to a loss of $4 \cdot 1$ person-years. After stratifying the morbidity cost with the severity of the disability, we found that the average losses of working years for the mildly, moderately, and severely disabled workers were $2.9,7.9$, and 17.6 person-years, respectively. During the past six years the annual morbidity cost for all disabled workers ranged from 19000 to 26000 person-years (table 7).

\section{Discussion}

In the estimation of the morbidity cost of occupational disability, difficulties and limitations do exist and need to be assessed. We could only focus on the metropolitan Taipei area and the number of workers selected was also limited to 114 due to the amount of time and effort we were able to offer for home visits. Nevertheless, the metropolitan Taipei area includes a wide variety of industries that are also widespread throughout the country, and the random selection we used provided us with a representative sample as was shown by the lack of obvious difference between the demographic data of the workers in our group and workers in the rest of the nation. ${ }^{3}$ Although about $30 \%$ of the workers were not interviewed, there was a significant difference in only the distribution of sex between those interviewed and those not interviewed. As sex was not found to be a main determinant in morbidity costs, we think that our results are acceptable.

The design of this study was retrospective, which was different from the four year follow

Table 8 Comparison of costs (in person-years) due to occupational mortality and disability in Taiwan, 1985-90

\begin{tabular}{lll}
\hline Calendar year & Mortality cost & Morbidity cost of disability \\
\hline 1985 & 32500 & 22400 \\
1986 & 32500 & 24200 \\
1987 & 36700 & 26500 \\
1988 & 43100 & 24700 \\
1989 & 44300 & 22300 \\
1990 & 43800 & 19200 \\
\hline
\end{tabular}

up recommended by Baker et al..$^{9}$ In our country it usually takes a long time (an average of 10.1 months) to receive disability compensation and there was about a six to 12 month time lag between the compensation payment and our interviews. Moreover, workers generally settle their compensation only if their disabilities have stabilised to avoid any future medical costs. Thus, it is reasonable to assume that the severity of the disability will not change appreciably after our interviews.

There might be some doubt about the legitimacy of the use of the proportion of decrease in monthly income as an index to estimate the degree of loss of productivity. We think that this is a reasonable method of estimation in Taiwan or in other developing countries without a comprehensive system of workmen's compensation. A large proportion of employers in Taiwan do not take full responsibility for workers with occupational disabilities, and those who do not pay much attention to occupational safety and health are more likely to have victims of injury. Instead of being transferred to another job with a similar income, workers who are injured might receive a lower salary when their jobs change, or are even laid off because of the change in their working capability. The disability compensation provided by the Labor Insurance Bureau is often the only payment they receive. Therefore our index is a reasonable estimate because the loss of productivity of the disabled workers is usually reflected in their monthly income.

Our ordinal logistic regression analysis showed that the three most significant factors for the decrease in monthly income were: the severity of the injury, the size of the factory, and age (table 5). The severity of the injury and age were probably the most important factors, because both of them are also the main predictors of the duration of morbidity (table 3). Fortunately, the models we used to predict national loss also contained these two factors (tables 3 and 6), which probably made our estimation of national morbidity cost due to occupational disability relatively accurate. 
Although we have tried to obtain more information from the Labor Insurance Bureau, it does not regularly collect data on the size of the factory. Failure to control for the determinants other than the severity of the injury and age, as well as the small number of subjects interviewed, might limit the generality of our conclusions. We think that our results of morbidity cost are unbiased but have a wide confidence interval (CI), and thus recommend a larger sample for future studies.

We have computed the working years of potential life lost (WYPLL) as an alternative way to estimate the indirect costs of occupational mortalities in our previous article. ${ }^{1} \mathrm{We}$ found that the WYPLL of occupational mortalities (in Taiwan) was about 38800 personyears annually. In this study, we have estimated the WYPLL of occupational disability in Taiwan and obtained a figure of about 23200 person-years annually. Thus the ratio of WYPLL between occupational mortality and disability was about 2:1 (table 8). The annual mortality cost showed a tendency to increase, a result that may be due to the large proportion of occupational fatalities ${ }^{1}$ from traffic accidents and an increase in the frequency of major occupational accidents at construction sites. On the contrary, the annual morbidity cost of occupational disability decreased yearly. The decrease in the proportion of workers in manufacturing industries as well as the migration of hazardous industries to neighbouring developing countries might contribute to the result.

The morbidity costs that we have calculated should not be considered to be the only loss to the victims of occupational injuries simply because effects such as pain, grief, and family or social disruption cannot be measured in these terms. ${ }^{9}$ Workers in developing countries like Taiwan still have extremely high risks in the working environment. Injured workers should be properly treated and receive enough compensation not only for their future but also the future of their family members. At the same time, a greater effort toward the prevention of occupational injuries must be implemented. The amount of disability compensation payment given to those who sustained injury was so limited that it only covered about one fifth the morbidity cost that we computed. ${ }^{16} \mathrm{We}$ recommend that our people, government, and employers make a joint effort to establish a more reasonable compensation payment.

1 Liu YH, Wang JD. Death due to occupational accidents and cost to society: an analysis of cumulative mortality rates and years of potential life loss. Fournal of the National Public Health Association (Republic of China) 1992;11:89-101.

2 The Bureau of Labor Insurance in Taiwan. Statistics of labor insurance in Taiwan 1986-91. Taipei: The Bureau of Labor Insurance in Taiwan, 1992.

3 Liu YH, Wang JD. Determinants and trends of occupational disability rates in Taiwan during 1985-1990. fournal of the National Public Health Association (Republic of China) 1993;12:354-67.

4 Waller JA. Occupational injuries. In: Waller JA. Injury control: a guide to the causes and prevention of trauma. Lexington, MA: Lexington Books, 1985:421-46.

5 Feyer AM, Williamson AM. A classification system for causes of occupational accidents for use in preventive strategies. Scand $f$ Work Environ Health 1991;17: 302-11.

6 Occupational injuries. In: David B, William F, Dennis M, eds. The National Committee for Injury Prevention and Control. (US) Injury Prevention: meeting the challenge. Am $\mathcal{F}$ Prev Med 1989:177-91.

7 Smith GS. Injuries as a preventable disease: the control of occupational injuries from the medical and public health perspective. Ergonomics 1987;30:213-20.

8 Department of Health, Executive Yuan, Taiwan Provincial Health Department, Taipei City Health Department. Kaohsiung City Health Department. Health and vital statistics: 1. General health statistics Taiwan Area, Republic statistics: 1. General health statistics Taiwan Area, Republic of China, 1985-90. Taipei: Division of St

9 Baker SP, O'Neill B, Karpf RS. The injury fact book. Lexington, MA: Lexington Books, 1984.

10 Harlan LC, Harlan WR, Parsons PE. The economic impact of injuries: a major source of medical costs. $A m \mathcal{F}$ Public Health 1990;80:453-59.

11 Rice DP, MacKenzie EJ, Jones AS, Kaufman SR, delissovoy GV, Smith GS, et al. Cost of injury in the United States: a report to congress. San Francisco: Institute fnited States: a report to congress. San for Health and Aging, University of California and Injury Prevention Cen

12 MacKenzie EJ, Siegel JH, Shapiro S, Moody M, Smith RT. Functional recovery and medical costs of trauma: an analysis by type and severity of injury. $\mathcal{f}$ Trauma an analysis by type

13 MacKenzie EJ, Shapiro S, Siegel JH. The economic impact of traumatic injuries: one-year treatment-related expenditures. $\mathcal{F A M A}$ 1988;260:3290-6.

14 SAS Institute. SAS/STAT User's Guide, release 6.03 edition. Cray, NC: SAS Institute, 1988.

15 SAS Institute. SAS/STAT Software: CALIS and LOGIS$T I C$ procedures, release 6.04. Cray, NC: SAS Institute, 1990:175-230. SAS Technical Report P-200.

16 The Bureau of Labor Insurance in Taiwan. The regulations of labor insurance. Taipei: The Bureau of Labor Insurance in Taiwan, 1989:38-79. 